\title{
Special Issue Editorial
}

\section{Subsequent Agreement and Practice in Treaty Interpretation}

\author{
Dai Tamada \\ Guest Editor, Professor of International Law, Graduate School of Law, Kobe \\ University, Japan \\ tamada@port.kobe-u.ac.jp
}

This special issue of the International Community Law Review brings together papers presented at the Kobe workshop on 'Subsequent Agreement and Practice in Treaty Interpretation', held on 18 December 2018 at Kobe University, with a further two contributions subsequently submitted by Professors Georg Nolte and Danae Azaria. It is a great honour to receive a contribution from none other than Professor Georg Nolte, the Special Rapporteur of the International Law Commission ('ILC') on that very topic.

Since 2008 the ILC has examined the topic 'Subsequent agreements and subsequent practice in relation to interpretation of treaties' ${ }^{1}$ and, finally, on 18 May 2018, it adopted the entire set of Draft Conclusions on its second reading. Subsequently, on 20 December 2018 - two days after the Kobe workshop the United Nations General Assembly adopted Resolution 73/202, by which it took note of the ILC's Draft Conclusions, and, furthermore, 'brought them to the attention of States and all who may be called upon to interpret treaties, and encouraged their widest possible dissemination.' ${ }^{2}$

The 2018 Kobe workshop provided us with the invaluable opportunity for jurists and practitioners, including public international law jurists and a Japanese government official (Ministry of Foreign Affairs), to discuss widely the ILC's Draft Conclusions. As is the case for all previous ILC studies, the ILC's Draft Conclusions are not immune from criticism, and, aiming to provide a leading opportunity for critical analysis, the Kobe workshop was held to discuss the likely theoretical and practical issues arising from the ILC's Draft Conclusions, and, by this, to elucidate their applicability in treaty interpretation.

1 As to the drafting of the Draft Conclusions, see the ILC's website: <http://legal.un.org/ilc/ guide/1_11.shtml>. The original title of this programme of work had been 'Treaties over time' which was changed to the present title in 2012.

2 A/RES/73/202 (20 December 2018), para. 4. 
In the introductory note, Georg Nolte, Special Rapporteur of the ILC, clarifies the background of the ILC's drafting process, and, in particular, that of fixing and amending the topic. More importantly, with regard to the contribution of the ILC's Draft Conclusions, he places emphasis on their 'practical relevance', in the sense that the Draft Conclusions, constituting 'authoritative commentaries or restatements', may help interpreters to identify and structure the list of issues relating to subsequent agreement and subsequent practice ('SASP'). Before jumping hastily to criticise the Draft Conclusions, therefore, it would be necessary to, first, correctly identify the original purpose and intent of the ILC. It would then be necessary to identify any theoretical issues surrounding the Draft Conclusions, and any practical difficulties in implementing the latter.

One of the more serious criticisms of the Draft Conclusions relates to the great difficulty in differentiating SASP from other notions, such as the modification of treaty provisions and evolutionary interpretation. This is analysed by Malgosia Fitzmaurice, who concludes that the boundaries between the various notions inter se are still 'blurred and ill-defined', and that this situation 'will remain' even after the adoption of the Draft Conclusions.

Another issue arising from the Draft Conclusions relates to the relationship between SASP of contracting States and the pronouncements of expert treaty bodies, and, in particular, those of human rights treaties. Danae Azaria analyses this issue by examining the positions of the ICJ and the ILC, to then conclude that, although the ICJ's position remains comparatively unclear, both, the ICJ and the ILC take into consideration the 'quality' of pronouncements, based on a common perception that international law is an integrated and cohesive legal system.

Were one to hastily jump to SASP in treaty interpretation without proper consideration, however, a risk to depart from the original intent of the contracting States and to admit 'de facto alteration of the original treaties' would sooner arise. Interestingly, such a practical concern is examined by Yukiya Hamamoto who analyses the potential limitations of the role of SASP, by providing concrete examples of treaties, such as the San Francisco Peace Treaty of 1952, which may not be subject to the application of SASP. This article sheds light on the profound challenge concerning the identification of the limitations of the Draft Conclusions.

The subsequent two articles aim at analysing the interpretation issue of particular treaties in the light of the Draft Conclusions, for elucidating their usefulness and limited scope. Mika Hayashi focuses on a multilateral treaty, namely, the Nuclear Non-Proliferation Treaty ('NPT'), and analyses the final documents adopted by the NPT Review Conferences. Contrary to the general 
perception that references to nuclear disarmament and Article VI in those documents amount to SASP, the author, applying two criteria from the Draft Conclusions, concludes that the documents in question do not constitute SASP. For his part, Dai Tamada focuses on a bilateral treaty, namely, the Japan-South Korea Claims Agreement of 1965 . Again, contrary to the wide-spread tendency of discussing SASP with regard to the 1965 treaty, the author clarifies the usefulness and limitations of SASP. While there has been no significant SASP capable of definitively contributing to the interpretation of that treaty, there is scope under 32 VCLT to discuss the same conducts of the parties.

The above two articles contribute to the discussion on how to implement the Draft Conclusions in actual treaty interpretation, and, at the same time, seek to highlight how difficult it is merely to rely on the Draft Conclusions. That said, it should be noted, however, that each article in this special issue is fully consonant with the original purpose of the Draft Conclusions, which, as explained by Georg Nolte in his Introductory Note, is to facilitate the identification of the relevant issues in treaty interpretation. 